\title{
Forum
}

PMIA invites members of the association to submit letters, printed and double-spaced, that comment on articles in previous issues or on matters of general scholarly or critical interest. The editor reserves the right to reject or edit Forum contributions and offers the PMLA authors discussed in published letters an opportunily to reply. The journal omits titles before persons' names, discourages footnotes, and does not consider any letter of more than one thousand words. Lelters should be addressed to PMLA Forum, Modern Language Association, 26 Broadway, 3rd floor, New York, NY 10004-1789.

\section{Defining the Canon}

\section{TO THE EDITOR:}

What a delight to read comments about the literary canon from correspondents in the PMLA Special Millennium Issue (115 [2000]: 1987-2076), where the educational and social benefits of "opening" the canon to women and minority and postcolonial writers are quite rightly a recurring theme, although there is little talk of a round-the-world canon and no prospect of reading forcign works in their original languages. While these shortcomings must have been obvious to many readers, an analysis of the letters discloses a subtler theme.

As most of the letters show, literary scholars tend to define the canon extensionally, in terms of examples or specimens, rather than intensionally, in terms of the attributes of a canonical work. Two features of extensional discourse are the use of specimens to define a universal category and the assumption that validity is derived by consensus among a totality of observers rather than from the conclusions of an ideal observer such as one finds in the allegory of the cave in Plato's Republic. The first of these is illustrated by Harold Bloom's The Western Canon, which devotes one chapter to each of twenty-six authors. Most critics probably agree that Bloom's concept of the canon is too narrow, but virtually every book and article about opening up the canon defines canon in terms of works that should or should not be included. As for consensus as the basis of validity, a sample of phrases from the Special Millennium Issue will illustrate: "We have begun to value the slave narrative" (Alfred Bendixen [2035]); "Other writers await our attention and inclusion in the canon" (John F. Crossen [2037]); "Postcolonial poetry has much to teach us" (Jahan Ramazani [2040]); "scholars must persuade teachers and administrators to include works from a variety of racial groups" (A. LaVonne Brown Ruoff [2040]). The plural pronouns and verbs imply that canon formation is a group effort, just as curriculum formation is a committee effort. Maybe canon is just a synonym for curriculum.

This presents certain philosophical problems. As Francesco Zanetti and I point out, in the extensional mode the concept of a canon is a logical impossi-

(OOO BY THE MODERN LANGUAGE ASSOCIATION OF AMERICA 
bility, even though, paradoxically, almost all modem discourse about literary canons takes place within this modality, probably because we regard extensionalisin. especially in its distributive form, ats anote scientific than the other modes of discourse (teall R. Anderson and Gianfrancesco Zanetti, "C umpanalle Semantic Approaches to the lded of a Litcrary Canon." Joumal of Aesthetion and Ar ('iricism 38 12000]: $341-60)$. When we think of the category "bird" in the extensional- clistributive modality. we think of robins, sparrows, penguins and so on without differentiating "typifying" or "canonical" birds from "atypical" or "marginal" birds. Every example of a bird belongs equally and alike to the category "birds"; there are no better. best, or bad instances of birds. So with works of literature: in the extensionaldistributive mode, every literary work is equally and alike a member of the sel or category mall we call "literature"; there are no better, best, or bad instances. In this mode, literature is a pile of books, and Bloom's Western Canon is fundamentally invalid, because it is not logically possible to exclude any literary work from the canon. Bendixen, writing about the American canon, states the problem: "Why has Faulkner replaced Hemingway as the premier modern American novelist? Why has Sherwood Anderson achieved a more significant place in our anthologies and literary histories than Sinclair Lewis. the first American to win the Nobel Prize in Literature?" He asks, "Can we articulate the relation between aesthetic value and literary history in any way that does not replace old essentialisms with new ones?" (2035). His questions imply that scholarly thinking about the canon needs to be concerned less with specimens and more with the attributes of canonicity. Zanetti and I go further, arguing that the idea of a literary canon can have validity only if defined in terms of its attributes, as Aristotle defines tragedy and epic in the Poetics.

Several Millennium Issue correspondents write in the extensional-collective mode, which implies a set of presuppositions according to which universals exist only as words-as a conventional way of speaking about individual things in relation to each other. The extensional-collective mode is apparent in the neohistoricist argument that the canon is a cultural convention, a strategy whereby the ruling class imposes its values and culture on society: thus,
Regenia (iagnier writes, "The literary canon as an elite cultural capital will probably cease to exist, except as a remnant of past bourgeois culture" (2038).

The tour discourse modalities-the extensionaldistributre onc of logical positivism, the extensionalcollective onc of nominalism (and of Michel Foucault), the inlensional-distributive one of Aristotke and the intensional-collective one of Plato-coexist in philosophy. in scholarly discourse, and in ordinary language, so it is not suprising to find writers switching modes. Rey Chow writes that a canon "is understood to include not merely a set of texts with quality proven over time but also the standards by which to evaluate such texts." "[S]et of texts" implies the extensional-distributive modality of set theory, while "standards," recalling the ancient Greek sense of canon as a rule or measure, implies an intensional modality. Then. too, Chow writes that "it is necessary to remember that a canon is a site of power that specializes in reinforcing the continuity of selected traditions and institutions," a neohistorical statement in the extensional-collective modality (2037). When viewed narrowly from the perspective of logic, the mixed modalities of her discourse seem like threc or four channels playing on a radio at the same time. But from the perspective of discourse analysis. they make perfect sense and illustrate our capacity to discourse in all four modes. The traditions of philosophy have historically privileged one or another of these modalities: the extensional-distributive is in favor at present. But because all four coexist in ordinary language and in human thinking, it is unlikely that any one will reign forever.

In our scholarly discourse about the literary canon, we should be aware of our presuppositions. If we define the canon in terms of specific texts that should or should not be in it, we are writing extensionally, either in the extensional-collective (nominalist) mode, in which canon is a label, not a substantive reality, or in the extensional-distributive (positivist) mode, in which the canon is the set of all literary works without exception. Canonicity and marginality are not logically possible in extensional discourse, but they alc possibic in intensional discourse, where universalis like lincrutare are definced in terms of attributes.

Earl R. Anderson

Cleveland State University 